\title{
Smoking in hospital: a survey of attitudes of staff, patients, and visitors
}

\author{
D. J. GARRATT, N. A. GOUGH, E. J. TAYLOR, M. H. BANKS, \\ AND P. H. SÖNKSEN
}

From the Departments of Medicine and Community Medicine, St. Thomas's Hospital Medical School, London

SUMMARY A survey was carried out on attitudes to smoking in hospital. Analysis of 411 interviews showed that the majority (64\%) of those questioned approved of some restrictions on patients smoking in the wards. Eighteen per cent would have liked to see a complete ban on smoking, while an identical number favoured no restrictions at all. Smoking habit influenced response; only $8 \%$ of smokers, compared with $25 \%$ of non-smokers, would have liked to see a total ban on smoking. Attitudes to smoking varied according to the status of the persons interviewed; only $6 \%$ of visitors and $7 \%$ of nurses approved of a complete ban on smoking, compared with $32 \%$ of medical students and $27 \%$ of doctors. The results suggest that the introduction of smoking and non-smoking areas in hospital wards would be approved by the majority of patients, staff, and visitors.

In view of the significant recent propaganda about smoking in public places, we decided to conduct our own survey on the attitudes of various groups of people directly or indirectly associated with the Lambeth Hospital (St. Thomas's Hospital Group). Recent statistics (Lee, 1976) show that in 1975, $61.5 \%$ of men and $43.4 \%$ of women in Britain smoked, and that the death rates from lung cancer and other lung diseases increase steeply with increasing consumption of cigarettes. In view of these findings, and the evidence that smoking is a contributory factor in the aetiology of other serious diseases (Royal College of Physicians, 1971), the question of restricting smoking in public places is clearly of great relevance. A total ban on smoking and on the sale of cigarettes in hospitals has already been recommended (World Health Organisation, 1975).

The aim of the survey was to investigate the smoking habits of a hospital population, and to examine the attitudes of staff, patients, and visitors towards smoking in hospital.

\section{Method}

The survey was carried out by 10 clinical students at the Lambeth Hospital, an acute general hospital with 177 beds, during one week in March, 1975. The students tried to question as many people as possible. All inpatients in the medical, surgical, and obstetric beds were interviewed, and the attitudes of visitors were sampled at random. No information was collected on the size of the complete sampling frame. A simple questionnaire, in three sections, was devised in a form suitable for computer analysis.

The first section recorded the person's age, sex, marital status, and occupation. Status within the hospital was divided into eight categories-medical, surgical, and obstetric patients, visitors, students, nurses, doctors, and ancillary staff. For patients, confinement to bed was recorded.

The second section dealt with smoking historysmoker, non-smoker, or ex-smoker; average consumption and in what form; age of starting and stopping regular smoking.

The last section asked: 'Do you think patients should be allowed to smoke in hospital?' Only one of the following answers was allowed. (1) Not at all (2) Only in certain areas (for example, in the dayroom, lavatory, etc.) but not on the general ward (3) On the ward but only at certain times (4) On the ward at any time.

A total of 411 questionnaires were completed. After social class coding according to the Registrar General's classification of occupations (Registrar General, 1970), the data were transferred to punched cards and analysed using standard statistical techniques.

\section{Results}

In analysing the results, the problems were that (1) the sample size was relatively small, so the number of people in some of the sub-groups was too 
small for statistical analysis and (2) the sample was unavoidably biased. A large number of nurses and medical students were questioned and most of them were aged 25 to 35 . The attitudes of the group of smokers may also have been influenced by the rather high percentage of doctors in the sample who smoked.

There was no statistically significant difference in attitude between the sexes, or between bed-bound and mobile patients.

The patients were divided into three groups, depending on whether they were medical, surgical, or obstetric cases, but these three groups appeared to have similar attitudes.

\section{EFFECT OF HOSPITAL STATUS ON}

\section{SMOKING HABIT}

Of the total sample of $411,41 \%$ were smokers, and $59 \%$ non-smokers. Corresponding proportions were found among the three groups of patients. The doctors interviewed, and the visitors, showed higher than average proportions of smokers $(57 \%$ and $56 \%$ respectively). The nurses, medical students, and ancillary workers showed lower than average proportions (30\%, $28 \%$, and $33 \%$ respectively).

If the visitors are taken as a control group, then all the other groups, apart from doctors, showed a lower proportion of smokers. This suggested that some patients may have given up smoking, perhaps after advice from their doctors, before going into hospital.

Indeed, 20 of the total of 185 patients (medical, surgical, and obstetric) had given up smoking in the last 12 months, compared with only eight of the 226 persons in the other groups of visitors, students, nurses, doctors, and ancillary staff $\left(\chi^{2}=16.05\right.$ $P<0 \cdot 01)$. Presumably this was the reason for the low proportion of smokers among the patients.

\section{ATTITUDE TO SMOKING ACCORDING TO CURRENT SMOKING HABIT}

A similar percentage of both smokers and nonsmokers $(45 \%$ and $48 \%$ respectively) thought that smoking should be allowed in specific areas (Table 1).

Table 1 Attitude to smoking according to current smoking habit

\begin{tabular}{lccc}
\hline & Smokers & Non-smokers & Total \\
\hline No smoking at all & $14(8)$ & $61(25)$ & 75 \\
Smoking in certain areas & $77(45)$ & $116(48)$ & 193 \\
Smoking at certain times & $33(19)$ & $35(15)$ & 68 \\
$\begin{array}{l}\text { Smoking at any time in any } \\
\text { place }\end{array}$ & $46(27)$ & $29(12)$ & 75 \\
Total & $170(100)$ & $241(100)$ & 411 \\
\hline
\end{tabular}

$x^{2}$ analysis indicates a highly significant effect of smoking habit on attitude to smoking in hospital $\left(x^{2}=29 \cdot 8 \mathrm{P}<0.001\right)$

This was the most popular of the four proposals put forward, and was chosen by $47 \%$ of those questioned.
The least popular proposal was that smoking should be allowed at specific times. Only $17 \%$ of those questioned chose this. Again, a similar percentage of both smokers and non-smokers made this choice (19\% and $15 \%$ respectively).

Eighteen per cent of the sample thought that smoking should not be allowed at all. However, only $8 \%$ of smokers opted for this proposal, compared with $25 \%$ of non-smokers.

Eighteen per cent of the sample thought that smoking should be allowed at any time in any place. Twenty-seven per cent of smokers chose this, but only $12 \%$ of non-smokers.

ATTITUDE TO SMOKING ACCORDING TO HOSPITAL STATUS

Again, the preference in all groups was for limiting smoking to certain areas (Table 2).

Table 2 Attitude to smoking according to hospital status

\begin{tabular}{lccccc}
\hline & $\begin{array}{l}\text { No smoking } \\
\text { at all }\end{array}$ & $\begin{array}{l}\text { Smoking } \\
\text { areas }\end{array}$ & $\begin{array}{l}\text { Smoking } \\
\text { at certain } \\
\text { times }\end{array}$ & $\begin{array}{l}\text { Smoking } \\
\text { at any time } \\
\text { in any place }\end{array}$ & Total \\
\hline Medical & $9(12 \cdot 5)$ & $34(47)$ & $12(17)$ & $17(29 \cdot 5)$ & 72 \\
Surgical & $15(21)$ & $22(31)$ & $16(23)$ & $17(24)$ & 70 \\
Obstetric & $7(16)$ & $20(47)$ & $7(16)$ & $9(21)$ & 43 \\
Visitor & $3(6)$ & $21(43)$ & $11(22)$ & $14(29)$ & 49 \\
Student & $16(32)$ & $28(56)$ & $3(6)$ & $3(6)$ & 50 \\
Nurse & $3(7)$ & $27(61)$ & $8(18)$ & $6(14)$ & 44 \\
Doctor & $10(27)$ & $17(46)$ & $6(16)$ & $4(11)$ & 37 \\
Ancillary & $12(26)$ & $24(52)$ & $5(11)$ & $5(11)$ & 46 \\
Total & 75 & 193 & 68 & 75 & 411
\end{tabular}

$x^{2}$ analysis indicates a highly significant effect of hospital status on attitude to smoking in hospital $\left(\left(x^{2}=43.8 \mathrm{P}<0.01\right)\right.$ Percentages in brackets.

Among hospital staff, nurses expressed a different attitude from other groups. Only $7 \%$ thought that smoking should not be allowed at all. Medical students were keenest to restrict smoking: $32 \%$ preferred to ban it completely and only $6 \%$ said that they would allow it at any time.

Patients expressed a more liberal attitude towards smoking than staff, but more patients than visitors were in favour of restrictions.

\section{EFFECT OF AGE ON SMOKING HABITS}

The highest proportion of smokers $(61 \%)$ was found in the age group 35 to 45 years. The lowest proportions were found in the youngest age group, 15 to $25,(35 \%)$ and in the oldest age group, 65 and over, (32\%). In the intermediate age groups, the proportions of smokers fell between these two extremes.

\section{EFFECT OF AGE ON ATTITUDES}

TO SMOKING

There was no obvious difference in attitudes to smoking at different ages. The views of those aged 15 to 25 and of those aged 65 and over were similar: most were in favour of restricting smoking to certain 
areas. In the age group 35 to 45 , an unusually high percentage of people said they would like a complete ban on smoking. This is difficult to explain, because it was in this age group that the highest proportion of smokers was found.

\section{Discussion}

Little research seems to have been done on attitudes to smoking in hospital. A similar survey was carried out among the hospital personnel only in a university medical centre in Germany (Abelin and Jossen, 1974). The prevalence of smoking was similar to that in our survey- $52 \%$ of (male) doctors and $34 \%$ to $36 \%$ of female personnel smoked. Twenty per cent wanted to ban smoking completely and $7 \%$ wanted no restrictions at all. Most were in favour of partial restrictions (such as confining smoking to defined areas, or allowing it at certain times).

Although we have undoubtedly sampled a group of doctors and nurses whose smoking habits are not typical of the professions as a whole (Doll and Peto, 1976), this did not materially affect our conclusions.

Some hospitals have already tried non-smoking wards and it appeared that patients appreciated this opportunity to give up smoking (Ball, 1973; Pang, 1973).

One of the arguments for allowing smoking in hospital is that it is a time of stress for most patients, and to prevent them from smoking would increase the stress. This was presumably the attitude of many nurses, since only $7 \%$ were in favour of restricting smoking completely.

One argument against allowing it is that smoking is harmful to health, so hospitals are the ideal places in which to discourage it.

There is no doubt that tobacco smoke can be upsetting to non-smokers and can physically affect them (Russell et al., 1973) especially if there is nowhere for them to escape from a smoky atmosphere.

No single solution can satisfy everyone, but the most popular suggestion is for smoking to be allowed only in certain areas (for example, day rooms or even one end of a large ward). In wards divided into bays, each containing a small number of beds, it should be possible to group smokers and non-smokers together, and keep the groups apart.

Reprints from Dr. P. H. Sönksen, Department of Medicine, St. Thomas's Hospital Medical School, London SE1 7EH.

\section{References}

Abelin, T., and Jossen, A. (1974). Unterlagen für Massnahmen zur Bekämpfung des Rauchens im Spital. Sozial und Präventivmedizin, 19, 47-53.

Ball, K. P. (1973). Smoking in hospitals. Letter: British Medical Journal, 3, 453.

Doll, R., and Peto, R. (1976). Mortality in relation to smoking. 20 years' observations on male British doctors. British Medical Journal, 2, 1525-1536.

Lee, P. N. (1976). Statistics of Smoking in the UK. Tobacco Research Council: London.

Pang, A. (1973). A no-smoking ward is possible. Postgraduate Medical Journal, 49, 682-683.

Registrar General (1970). Classification of Occupations. HMSO: London.

Royal College of Physicians (1971). Smoking and Health Now. Pitman: London.

Russell, M. A. H., Cole, P. V., and Brown, E. (1973). Absorption by non-smokers of carbon monoxide from room air polluted by tobacco smoke. Lancet, 1, 576-579.

World Health Organisation (1975). Smoking and its effects on health. Technical Report Series No. 568. WHO: Geneva. 